\section{Vietnam Journal of Agricultural Sciences}

Received: March 19, 2018

Accepted: September 07, 2018

\section{Correspondence to}

tdanh.cnsh@vnua.edu.vn

\section{ORCID}

Thi Bich Thuy Nguyen https://orcid.org/0000-0003-18356999

Xuan Canh Nguyen

https://orcid.org/0000-0002-77916397

\title{
Studies on the Biological Characteristics of the Bt116 Lingzhi Mushroom Strain (Tomophagus sp.) Collected in Hanoi
}

\section{Tran Dong Anh, Nguyen Ngo Minh Nhat, Ngo Xuan Nghien, Nguyen Thi Bich Thuy, Nguyen Thi Luyen and Nguyen Xuan Canh}

Faculty of Biotechnology, Vietnam National University of Agriculture, Hanoi 131000, Vietnam

\begin{abstract}
In this study, an unknown mushroom species collected on rotting trunks of Ficus elastica in the Hanoi Botanical Garden was investigated. It was designated as Bt116. Based on the observed morphological characteristics, such as irregularly semi-circular, slightly yellow pileus; very soft, homogeneous, spongy, creamy white context; short and not clear stipes; and basidiospores typical of ganoderma mushrooms, etc., we hypothesized that Bt116 belongs to the Tomophagus Murr. mushroom genus. Some biological characteristics of the Bt116 strain were made. The results indicated that the temperature $35^{\circ} \mathrm{C}$ was optimal for Bt116 mycelial growth; an alkaline environment $(\mathrm{pH}$ 8.0) was conducive for the mycelial growth of Bt116 among a range of $\mathrm{pH}$ levels from 4.0 to 9.0; aerobic conditions were better than anaerobic conditions for the growth of Bt116 mycelium; and lighting time showed no significant effects on the growth of Bt116 mycelium.
\end{abstract}

\section{Keywords}

Tomophagus Murr, Bt116 Lingzhi, biological characteristic, temperature, $\mathrm{pH}$ levels

\section{Introduction}

Ganodermataceae have been designated as a mushroom family with high medicinal potentiality. Studies on many members of this family pointed out that they contain hundreds of bioactive compounds which are great interest for medicinal and pharmaceutical purpose, e.g., Amino acid, Triterpenes, and Triterpenoids (Huie and $\mathrm{Di}, 2004$ ). Therefore, consuming these mushrooms can help our body reduce cholesterol levels, improve immune system, cure cancer, and fight depression, etc.

Tomophagus Murr. is one of the eight genera in the Ganodermataceae family. Therefore, members of this genus may be potential candidates to be used as medicines. For example, 
Tomophagus cattienensis has been shown to contain many rare bioactive compounds, especially cattienoid B which can kill epithelium cancer cells (Hien et al., 2013). A recent study has reported several new lanostane triterpene lactones from the cultivated $T$. colossus strain (El Dine et al., 2008). In addition, Tomophagus is a rare mushroom genus. Until now, only three species of this genus have been reported, T. colossus, $T$. cattienensis, and Tomophagus sp. Nov.

An unknown mushroom species collected on the rotting trunks of Ficus elastica in the Hanoi Botanical Garden, designated as Bt116, contains morphological characteristics similar to the fruiting bodies of Tomophagus species. If our hypothesis is true, this is the first time a species of Tomophagus has been reported in Northern Vietnam. This is important evidence showing the wide adaptive ability of Bt116 to different weather conditions of Vietnam. Therefore, the goals of this paper were to investigate the biological characteristics of this mushroom, identify this mushroom's species, and support future research as well as the cultivation of this rare, potential medicinal mushroom.

\section{Materials and Methods}

The unnamed mushroom species was collected on the rotting trunks of Ficus elastica in the Hanoi Botanical Garden and was designated as Bt116. Collection, anatomization, and morphological evaluation of the mushroom sample were made as described by Kiet (2011). The mushroom samples were identified based on the morphological and microscopic characteristics using standard descriptions of the species.

The growth of Bt116 mycelia was investigated as described by Kapoor and Sharma, (2014):

Temperature effects: The cultures of Bt116 were grown on Petri dishes containing PDA medium at different temperature, viz., $5^{\circ} \mathrm{C}$, $10^{\circ} \mathrm{C}, 15^{\circ} \mathrm{C}, 20^{\circ} \mathrm{C}, 25^{\circ} \mathrm{C}, 30^{\circ} \mathrm{C}$, and $35^{\circ} \mathrm{C}$, using an incubator. Each treatment was replicated three times.
pH level effects: The cultures of Bt116 were grown on Petri dishes containing PDA medium at the different $\mathrm{pH}$ levels of 4.0, 5.0, 6.0, 7.0, 8.0, and 9.0. Each treatment was replicated three times.

Lighting time effects: The cultures of Bt116 were grown on Petri dishes containing PDA medium under different light conditions, viz., 0 hours of light a day, 12 hours of light a day, and 24 hours of light a day. Each treatment was replicated three times.

Aeration rate effects: The cultures of Bt116 were grown on sealed and unsealed Petri dishes. Both treatments contained PDA medium. Each treatment was replicated three times.

Treatments were arranged in a completely randomized design. Analysis of variance (ANOVA) test was run on the data and significance was determined using the least significant differences (LSD) test analysis at the 0.05 probability level. All analyses were conducted by IRRISTAT 5.0.

\section{Results and Discussion}

\section{Identification}

The first step in identifying Bt116 was documenting its morphological characteristics. The context is very soft, homogeneous and spongy; creamy white to ivory in color; and the maximum thickness is around $5 \mathrm{~cm}$. The tube layer is thin (about $2 \mathrm{~cm}$ ) with small round pores (3-4 pores $\mathrm{mm}^{-1}$ ). The tube layer is dark brown while the pores have an ivory surface.

The stipe is crusty, very short, and thick, and slightly laccate in appearance (Figure 1). The mycelium is thin, similar to that of Ganoderma lucidum in the mature stage of development, and there is a presence of rounds which contain the chlamydospores; the color is creamy white at first then becomes dark ivory (Figure 2). The basidiospore is typical of ganoderma mushrooms with an ellipsoid shape, and thin double-layered wall containing small angular drops in the apex. The color is slightly dark brown, 15-17 $\mu \mathrm{m}$ in length, and 10-12 $\mu \mathrm{m}$ in diameter (Figure 3). The chlamydospore is globular with the surface covered by a layer of tiny spines. The color ranges from dark navy to black (Figure 4). 


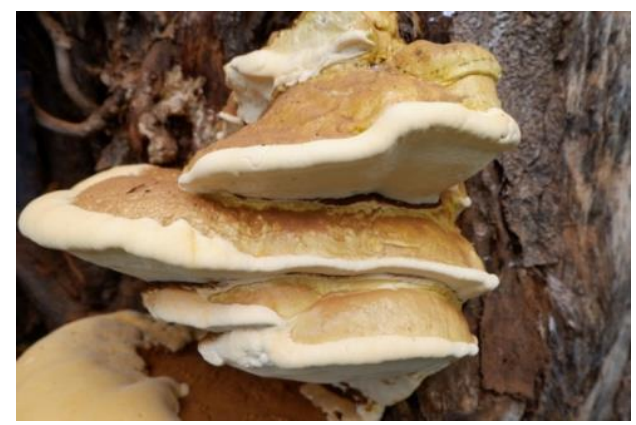

Figure 1. The pileus of Bt116

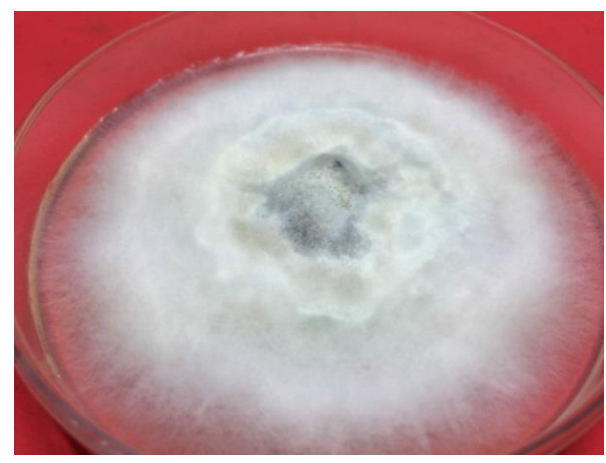

Figure 2. The mycelium of Bt116

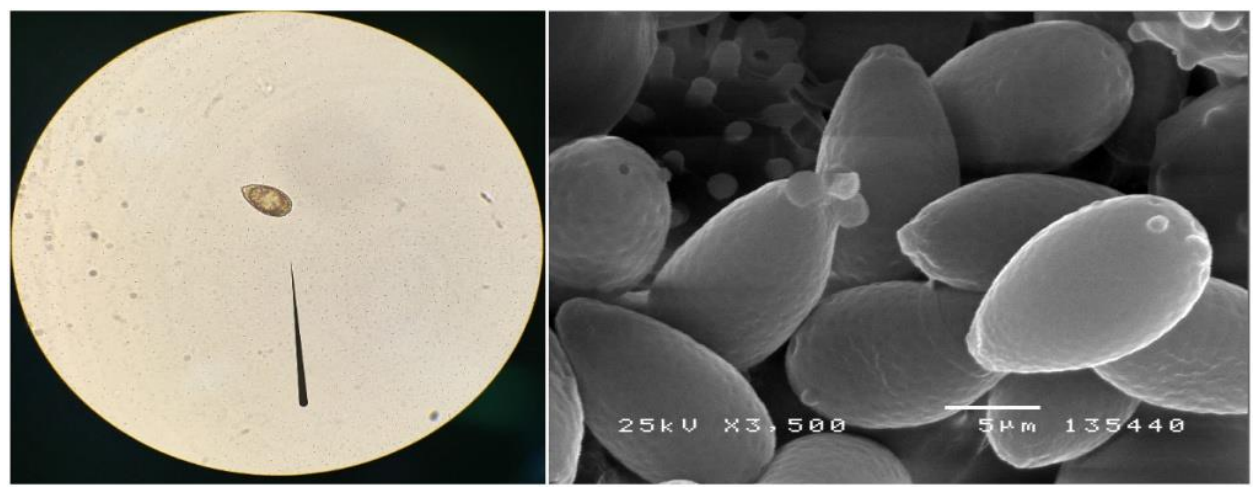

Figure 3. The basidiospore of Bt116 observed with an optical microscope at 100x magnification (left) and scanning electron microscope at 3500x magnification (right)

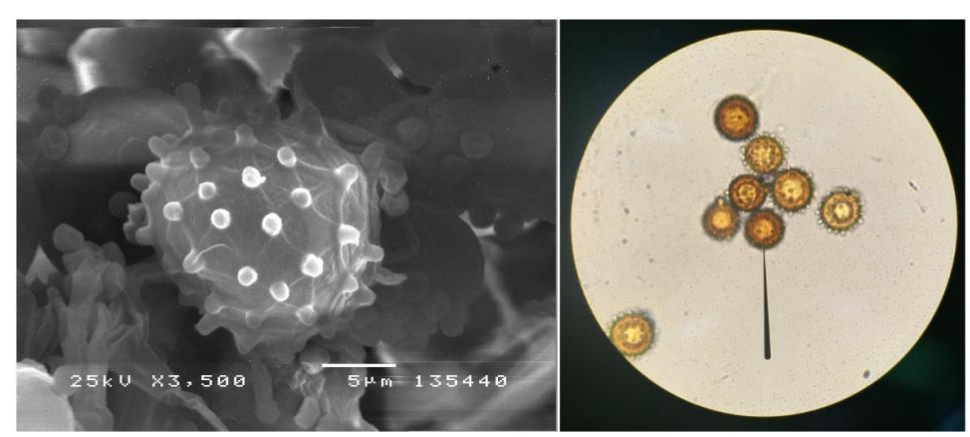

Figure 4. The chlamydospore of Bt116 observed with an optical microscope at 100x magnification (right) and scanning electron microscope at 3500x magnification (left) 
In comparison with the genus Tomophagus, the characteristics of the Bt116 pileus are similar to those of $T$. colossus which were described by Kiet (2011) as fairly loose, soft in consistency, light-weighted, irregularly semicircular and slightly ungulate, and with a glabrous, yellowish brown, and irregularly swollen crust. The Bt116 context clearly differs morphologically from Tomophagus sp. Nov. (Duong et al., 2014) and T. cattienensis (Tham et al., 2012) which were described as changing their colors when dry. The Bt116 context is similar to that of $T$. colossus which was described by Kiet (2011) as spongy, soft in shape, up to $5 \mathrm{~cm}$ in thickness, and creamy white in color. The Bt116 tube layer is similar to the specific tube layer characteristics of Tomophagus, which were described as thin in shape, grey brown to cinnamon brown in color, and containing small (2-3 pores $\left.\mathrm{mm}^{-1}\right)$ round or angular pores. The mycelium of Bt116 is similar to the specific mycelium characteristics of Tomophagus, especially in the appearance of rounds containing the chlamydospores. The Bt116 basidiospore is most similar to that of $T$. colossus which was described by Kiet (2011) as ellipsoid or broadly ellipsoid, truncate at its apex, double-walled, containing one big oily drop; $15-19 \times 10-12 \mu \mathrm{m}$ in size; and yellowish brown in color. The Bt116 chlamydospore is similar to that of $T$. colossus which was described by Kiet (2011) as globular in shape with the surface covered by multiple micro stipes. After comparing the observed morphological characteristics of Bt116 and earlier reports, we believe that Bt116 belongs to the genus Tomophagus.

\section{Temperature effects}

Temperature is one of the important factors for the growth of fungi. A number of studies have shown the effects of temperature on members of the Ganodermataceae family. Singh et al. (2015) reported that the optimum temperature for Ganoderma lucidum was $30 \pm$ $1^{\circ} \mathrm{C}$. In this study, we investigated the growth of Bt116's mycelia at five different temperatures, viz. $15^{\circ} \mathrm{C}, 20^{\circ} \mathrm{C}, 25^{\circ} \mathrm{C}, 30^{\circ} \mathrm{C}$, and $35^{\circ} \mathrm{C}$, on PDA medium. The results are shown in Table 1 and Figure 5.

According to Table 1 and the LSD analysis of the data at a $5 \%$ level of significance, there was no mushroom growth at $15^{\circ} \mathrm{C}$. This means that the mushroom only grows in temperatures above $15^{\circ} \mathrm{C}$. When the temperature increased from $20^{\circ} \mathrm{C}$ to $35^{\circ} \mathrm{C}$, the diameter of the mycelia after seven days of culture (DMC) increased from $2.31 \mathrm{~cm}$ to 5.96 $\mathrm{cm}$, respectively. The mean DMC was $3.88 \mathrm{~cm}$. There was no clear difference in the DMCs between $15^{\circ} \mathrm{C}$ and $20^{\circ} \mathrm{C}$ which were $2.31 \mathrm{~cm}$ and $2.88 \mathrm{~cm}$, respectively. The data also indicated that a temperature range of $30-35^{\circ} \mathrm{C}$ was optimum for $\mathrm{Bt} 116$ in terms of the DMC. In regards to the time for complete plate colonization (TCC), when the temperature increased from $20^{\circ} \mathrm{C}$ to $35^{\circ} \mathrm{C}$, the TCC decreased from 23.17 days to 10.00 days, respectively. The mean TCC was 16.21 days. The data also indicated that a temperature range of 30$35^{\circ} \mathrm{C}$ was optimum for the TCC of Bt116. When the temperature increased from 20 to $35^{\circ} \mathrm{C}$, the DMC increased progressively. The density of mycelia (DOM) was highest at $35^{\circ} \mathrm{C}$ and lowest at $20^{\circ} \mathrm{C}$. The DOM of $\mathrm{Bt} 116$ at $25^{\circ} \mathrm{C}$ and $30^{\circ} \mathrm{C}$ were not significantly different (Figure 5).

Table 1. The effects of temperature on mycelial growth

\begin{tabular}{|c|c|c|c|}
\hline $\begin{array}{ll}\text { Temperature } & \text { Factors }\end{array}$ & $\begin{array}{l}\text { Diameter of mycelia after seven } \\
\text { days of culture }(\mathrm{cm})\end{array}$ & $\begin{array}{l}\text { Time for complete plate } \\
\text { colonization (days) }\end{array}$ & $\begin{array}{c}\text { Density o } \\
\text { mycelia }\end{array}$ \\
\hline $15^{\circ} \mathrm{C}$ & - & - & \\
\hline $20^{\circ} \mathrm{C}$ & $2.31 \pm 0.03$ & $23.17 \pm 2.25$ & + \\
\hline $25^{\circ} \mathrm{C}$ & $2.88 \pm 0.06$ & $18.67 \pm 0.47$ & ++ \\
\hline $30^{\circ} \mathrm{C}$ & $4.39 \pm 0.17$ & $13.00 \pm 0.00$ & ++ \\
\hline $35^{\circ} \mathrm{C}$ & $5.96 \pm 0.13$ & $10.00 \pm 0.00$ & +++ \\
\hline $\mathrm{LSD}_{0.05}$ & 0.26 & 2.65 & \\
\hline CV\% & 3.6 & 8.7 & \\
\hline
\end{tabular}




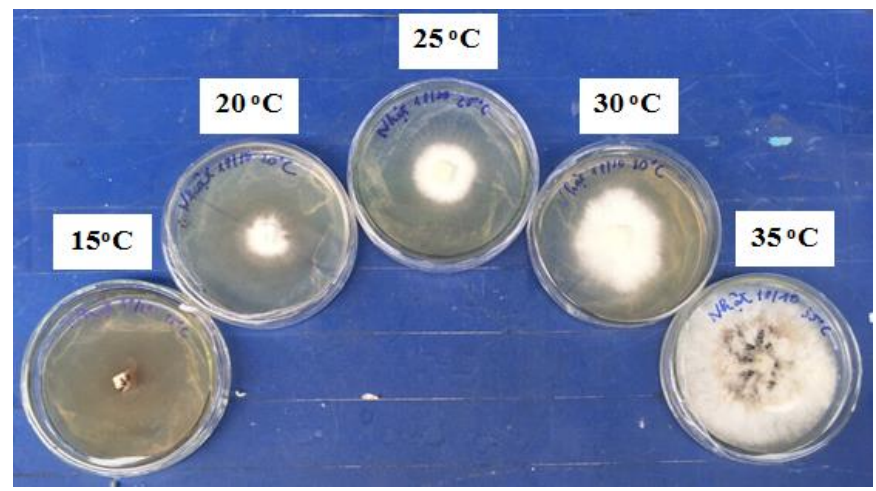

Figure 5. The effects of temperature on mycelial growth

In conclusion, the optimum temperature range for Bt116 mycelial growth was $30-35^{\circ} \mathrm{C}$. This result could be considered as the reason why Tomophagus spp. are only reported throughout the tropics.

\section{pH level effects}

$\mathrm{pH}$ is also an important factor for the growth of fungi. Rai (2003) reported that mycelial growth of Ganoderma lucidum was greatest at an acidic $\mathrm{pH}$. In addition, Veena and Pandey (2006) reported the $\mathrm{pH}$ range of 4.0-6.5 was the best for the growth of G. lucidum. The maximum mycelial growth of G. lucidum was recorded when the $\mathrm{pH}$ of the substrate was 5.0 (Kapoor and Sharma, 2014). In this study, we investigated the growth of Bt116's mycelia at six different $\mathrm{pH}$ levels, viz. 4.0, 5.0, 6.0, 7.0, 8.0, and 9.0, on PDA medium. The results are shown in Table 2 and Figure 6.

According to Table 2 and the LSD analysis of the data at a $5 \%$ level of significance, the
DMC at different $\mathrm{pH}$ levels were significantly distinct with acceptable coefficients of variation. The DMC increased progressively when the $\mathrm{pH}$ level increased from 4.0 to 8.0 then dropped when the $\mathrm{pH}$ level reached 9.0.

The mean DMC was $3.73 \mathrm{~cm}$. The highest DMC was recorded at $\mathrm{pH} 8.0(4.35 \mathrm{~cm})$, and the lowest DMC was recorded at $\mathrm{pH} 4.0(2.49 \mathrm{~cm})$. A pH range of 5.0-9.0 was optimum for the DMC of Bt116. There were no clear differences among the DMCs at $\mathrm{pH} 5.0(3.73 \mathrm{~cm}), \mathrm{pH} 6.0$ $(4.13 \mathrm{~cm}), \mathrm{pH} 7.0(3.96 \mathrm{~cm})$, and $\mathrm{pH} 9.0(3.72$ $\mathrm{cm})$. The TCC decreased progressively when the $\mathrm{pH}$ level increased from 4.0 to 8.0 then increased when the $\mathrm{pH}$ level reached 9.0. The mean TCC was 17.21 days. The highest TCC was recorded at $\mathrm{pH} 8$ with 14.17 days while the lowest DMC was recorded at $\mathrm{pH} 4.0$ with 25.00 days. A pH range of 5.0-9.0 was optimum for the TCC of Bt116. There were no clear differences among the TCCs at $\mathrm{pH} 6.0$ (14.83 days), $\mathrm{pH} 7.0$ (14.33 days), $\mathrm{pH} 8.0$ (14.17 days),

Table 2. The effects of $\mathrm{pH}$ levels on mycelial growth

\begin{tabular}{|c|c|c|c|}
\hline pH levels & $\begin{array}{l}\text { Diameter of mycelia after seven days } \\
\text { of culture }(\mathrm{cm})\end{array}$ & $\begin{array}{l}\text { Time for complete plate } \\
\text { colonization (days) }\end{array}$ & $\begin{array}{c}\text { Density of } \\
\text { mycelia }\end{array}$ \\
\hline 4 & $2.49 \pm 0.11$ & $25.00 \pm 0.72$ & ++ \\
\hline 5 & $3.73 \pm 0.26$ & $20.11 \pm 2.67$ & ++ \\
\hline 6 & $4.13 \pm 0.10$ & $14.83 \pm 0.23$ & ++ \\
\hline 7 & $3.96 \pm 0.31$ & $14.33 \pm 0.23$ & ++ \\
\hline 8 & $4.35 \pm 0.18$ & $14.17 \pm 0.24$ & +++ \\
\hline 9 & $3.72 \pm 0.26$ & $14.83 \pm 0.23$ & + \\
\hline $\mathrm{LSD}_{0.05}$ & 0.48 & 2.5 & \\
\hline CV\% & 7.3 & 8.2 & \\
\hline
\end{tabular}




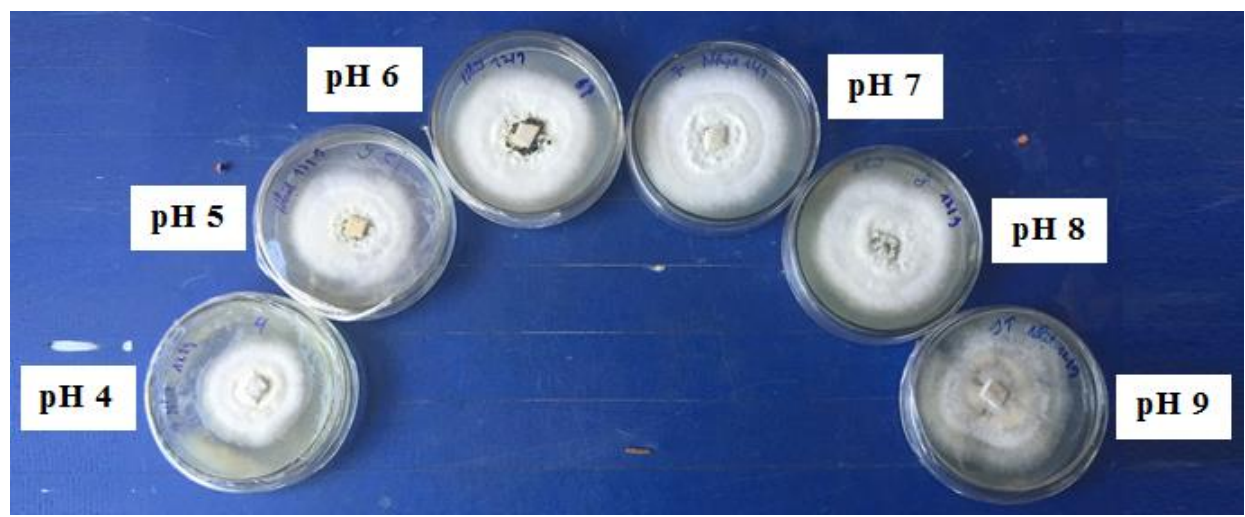

Figure 6. The effect of $\mathrm{pH}$ levels on mycelial growth

and $\mathrm{pH} 9.0$ (14.83 days). The DOM increased progressively when the $\mathrm{pH}$ level increased from 4.0 to 8.0 then dropped when the $\mathrm{pH}$ level reached 9.0. The DOM was the highest at $\mathrm{pH}$ 8.0 and lowest at $\mathrm{pH} 9.0$. The DOM of Bt116 at $\mathrm{pH} 4.0, \mathrm{pH} 5.0, \mathrm{pH} 6.0$, and $\mathrm{pH} 7.0$ were at a moderate level (Figure 6).

In conclusion, Bt116 was able to grow over a wide range of $\mathrm{pH}$ levels (from 4.0 to 9.0). The optimum $\mathrm{pH}$ level for Bt116 was 8.0. This result has been found in most mushroom species reported in earlier research, except for $G$. lucidum which grew and performed well at a $\mathrm{pH}$ near neutral or lightly acidic.

\section{Lighting time effects}

Despite the fact that there are no chloroplasts in mushrooms, light also affects the growth and development of many mushroom species. According to Jang et al. (2013), the cultivation of Hypsizygus marmoreus coupled with exposure to blue LED was useful for inducing high quality fruiting bodies as well as higher levels of ergosterol. Wang et al. (2011) reported that the mycelium of Ganoderma lucidum grew faster under red LED, blue LED, and in dark conditions, compared to other light qualities. In this study, we investigated the growth of Bt116's mycelia at three different lighting times, viz., $0 \mathrm{~h}$ per day, $12 \mathrm{~h}$ per day, and $24 \mathrm{~h}$ per day, on PDA medium. The results are shown in Table 3 and Figure 7.

According to Table 3, the LSD analysis of data at a $5 \%$ level of significance showed that the DMC and TCC under different lighting time conditions were not significantly different.
The DOM increased progressively when the lighting time decreased from 24 hours per day to 0 hours per day. These results mean that the DOM was highest under the conditions of 0 hours of light per day and lowest under the conditions of 24 hours of light per day. The DOM under the conditions of 12 hours of light per day was at a moderate level (Figure 7). In conclusion, the effects of lighting time on the growth of Bt116 were not significant except for in the DOM.

\section{Aeration rate effect}

Respiration is a very important process for the survival of mushrooms. The concentration of $\mathrm{O}_{2}$ and $\mathrm{CO}_{2}$ in the environment can have significant effects on the growth and development of mushrooms as too much $\mathrm{CO}_{2}$ inhibits fruiting, especially the development of the fruiting body. The mycelial growth of Flammulina velutipes and Pleurotus ostreatus had no significant differences between different levels of $\mathrm{CO}_{2}$ concentration $\left(550 \mu \mathrm{L} \mathrm{L}^{-1}, 3000\right.$ $\mu \mathrm{L} \mathrm{L}^{-1}, 6000 \mu \mathrm{L} \mathrm{L}^{-1}$ and $9000 \mu \mathrm{L}^{-1}$ ) (Kinugawa et al., 1994). In this study, we investigated the growth of Bt116's mycelia under anaerobic conditions and aerobic conditions with sealed and unsealed Petri dishes, respectively. The results are shown in Table 4 and Figure 8. The DMCs under different aeration rates were significantly different with acceptable coefficients of variation. According to the results, the mean DMC was $5.17 \mathrm{~cm}$. The DMC under aerobic conditions $(5.74 \mathrm{~cm})$ was higher than that of anaerobic conditions $(4.61 \mathrm{~cm})$ (Table 4). The 
TCC values under different aeration rates were also significantly different with acceptable coefficients of variation. The mean TCC was 15.22 days. The TCC under anaerobic conditions (16.56 days) was higher than that under aerobic conditions (13.89 days). In conclusion, the aerobic conditions were optimum for the growth of Bt116 (Figure 8).

Table 3. Investigation of the effects of lighting times on mycelial growth

\begin{tabular}{|c|c|c|c|}
\hline Lighting times Factors & $\begin{array}{l}\text { Diameter of mycelia after seven } \\
\text { days of culture }(\mathrm{cm})\end{array}$ & $\begin{array}{l}\text { Time for complete plate } \\
\text { colonization (days) }\end{array}$ & $\begin{array}{c}\text { Density of } \\
\text { mycelia }\end{array}$ \\
\hline 24 lighting hours per day & $5.51 \pm 0.42$ & $11.83 \pm 0.24$ & + \\
\hline 12 lighting hours per day & $5.68 \pm 0.19$ & $11.33 \pm 0.23$ & ++ \\
\hline 0 lighting hours per day & $5.53 \pm 0.13$ & $11.67 \pm 0.24$ & +++ \\
\hline $\operatorname{LSD}_{0.05}$ & 0.68 & 0.58 & \\
\hline CV\% & 6.1 & 2.5 & \\
\hline
\end{tabular}

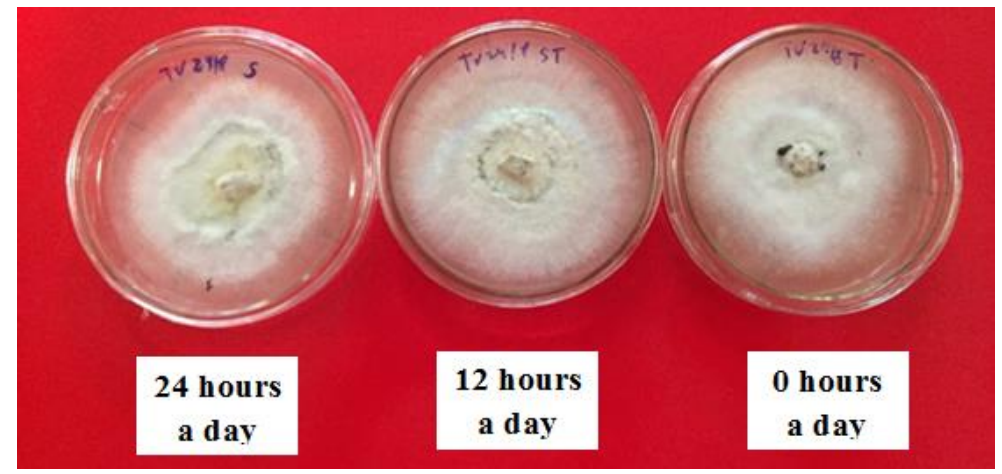

Figure 7. The effects of lighting times on mycelial growth

Table 4. The effects of aeration rates on my celial growth

\begin{tabular}{|c|c|c|c|}
\hline Aeration rates $\quad$ Factors & $\begin{array}{l}\text { Diameter of mycelia after seven } \\
\text { days of culture }(\mathrm{cm})\end{array}$ & $\begin{array}{l}\text { Time for complete plate } \\
\text { colonization (days) }\end{array}$ & $\begin{array}{l}\text { Density of } \\
\text { mycelia }\end{array}$ \\
\hline Anaerobic conditions & $4.61 \pm 0.24$ & $16.56 \pm 0.15$ & ++ \\
\hline Aerobic conditions & $5.74 \pm 0.23$ & $13.89 \pm 0.42$ & +++ \\
\hline $\mathrm{LSD}_{0.05}$ & 0.64 & 0.87 & \\
\hline CV\% & 5.5 & 2.5 & \\
\hline
\end{tabular}

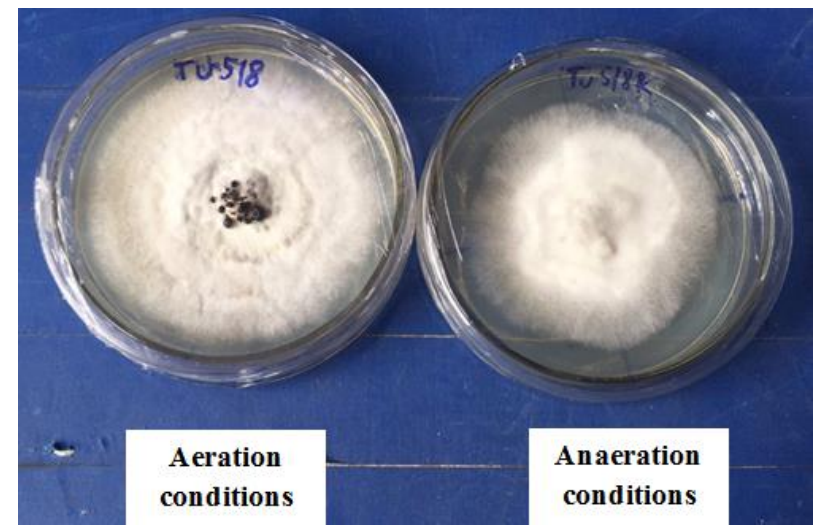

Figure 8. The effect of aeration rates on mycelial growth 


\section{Conclusions}

Based on the observed morphological characteristics, such as irregularly semi-circular, slightly yellow pileus; very soft, homogeneous, spongy, and creamy white contexts; short and not clear stipes; and basidiospores typical of other ganoderma mushrooms, etc., we believe that Bt116 belongs to the genus Tomophagus. The mycelia growth performed well at a temperature range of $30-35^{\circ} \mathrm{C}$ and reached a maximum rate at $35^{\circ} \mathrm{C}$. However, Bt116 can survive in lower temperatures as long as they are above $15^{\circ} \mathrm{C}$. Compared to the weather of Vietnam, the favorable habitats of Bt116 are the Central and Southern regions. In Northern Vietnam, Bt116 can grow and develop nearly all year round except for winter. Bt116 grew and performed well at $\mathrm{pH}$ values near to neutral or light alkaline $(\mathrm{pH}$ 5.0-9.0). The optimal $\mathrm{pH}$ level for Bt116 was 8.0. The wide range of variation in temperature requirements contributes to the diversity in distribution of Bt116. The aerobic condition was optimal for the growth of Bt116. The lighting time factor was shown to have no significant impact on the growth of Bt116.

\section{References}

Duong P. N, Anh N. T, Duy V. D and Tham L. X. (2014). A new Tomophagus species from Cat Tien national park of Vietnam based on the evidence from morphology and its DNA barcodes. The $6^{\text {th }}$ National scientific conference on Ecology and Biological resources. pp. 55-62 (in Vietnamese).

El Dine S. R., El Halawany M. A., Nakamura N., Ma C. M. and Hattori M. (2008). New lanostane triterpene lactones from Vietnamese mushroom Ganoderma colossum (Fr.) C.F. Baker. Chemical and Pharmaceutical Bulletin. Vol 56. pp. 642-646.

Jang M. J., Lee Y. H., Ju Y. C., Kim S. M. and Koo H. M. (2013). Effect of Color of Light Emitting Diode on
Development of Fruit Body in Hypsizygus marmoreus. Mycobiology. Vol 41 (1). pp. 63-66.

Hien B. T. T., Hoa L. T. P, Tham L. X and Quang D. N (2013). Cattienoids A-C, three novel steroids from the mushroom Tomophagus cattienensis. Fitoterapia. Vol 91. pp. 125-127.

Huie C. W. and Di X. (2004). Chromatographic and electrophoretic methods for Lingzhi pharmacologically active components. Journal of Chromatography B. Vol 812 (1). pp. 241-257.

Kapoor P. and Sharma B. M. (2014). Studies on different growth parameters of Ganoderma lucidum. International Journal of Science, Environment and Technology. Vol 3 (4). pp. 1515-1524.

Kiet T. T (2011). Macro fungi of Viet Nam, Vol 1. Publishing House for Science and Technology. 314 pages (in Vietnamese).

Kinugawa K., Suzuki A., Takamatsu Y., Kato M. and Tanaka K. (1994). Effects of concentrated carbon dioxide on the fruiting of several cultivated basidiomycetes (II). Mycoscience. Vol 35 (4). pp. 345-352.

Rai R. D. (2003). Successful cultivation of the medicinal mushroom Reishi, Ganoderma lucidum in India. Mushroom Research. Vol 12. pp. 87-91.

Singh J., Singh S., Kumar A. and Singh F. (2015). Effect of temperature and $\mathrm{pH}$ on mycelial growth of Ganoderma lucidum (Leyss. ex Fr. Karst). International Journal of Tropical Agriculture. Vol 33 (2) (Part III). pp. 1279-1282.

Tham L. X., Hung N. L. Q, Duong P. N., Hop D. V., Dentinger B. T. M. and Moncalvo J. M. (2012). Tomophagus cattiennensis sp. nov., a new Ganodermataceae species from Vietnam: Evidence from morphology and ITS DNA barcodes. Mycological Progress. Vol 11 (3). pp. 775-780. doi: 10.1007/s11557-011-0789-3.

Veena S. S. and Pandey M. (2006). Evaluation of the locally available substrates for the cultivation of indigenous Ganoderma isolates. Journal of Mycology and Plant Pathology. Vol 36 (3). pp. 434 $-438$.

Wang L., Chen X., Wang Q., Hao J. and Lan J. (2011). Effect of different light of LED light quality on growth and antioxidant enzyme activities of Ganoderma lucidum. China Journal of Chinese Materia Medica. Vol 36 (18). pp. 2471-2474. 